\title{
Parachute Suture Technique with Arteriotomy by using Aortic Punch in Live Related Renal Transplant
}

\section{Abudar Al-Ganadi*, Mushtaq Alhamati, Nabeel Mughales and Abdulwahed Algunaid}

Yemen International Hospital, Faculty of Medicine, Taiz University, Taiz, Yemen

\begin{abstract}
Objective: To provide review of our experience in vascular anastomosis technique for kidney transplantation patients.

Material and Methods: 100 chronic kidney disease patients 89 males and 11 females with mean age $23.5 \pm 3$ years have been operated for kidney transplantation from January 2011 through April 2015. Vascular part of operation was done using parachute suture technique and arteriotomy by aortic punch. Recipients were prospectively entered into a database and retrospectively reviewed. Data collected included the warm and cold ischemic time, arterial and venous anastomotic time, color Doppler ultrasonography examination of the anastomosis site on 1, 7 postoperative days, mean serum creatinine level on 3, 14 days after the operation and any early or late postoperative complications.
\end{abstract}

Results: Mean kidney warm and cold ischemia time was $7.5 \pm 4$ minutes and $21.5 \pm 7$ minutes respectively. Mean arterial and venous anastomotic time was $7.2 \pm 9$ minutes and $8 \pm 4$ minutes respectively. All allografts had single artery. Renal arteries were anastomosed to (53\%) common iliac arteries, (40\%) external iliac arteries, $(6 \%)$ internal iliac arteries and just (1\%) to lower aorta in recipients; however, allograft renal veins were anastomosed to (95\%) common iliac vein and (5\%) inferior vena cava recipients.

No vascular complications were detected in the early postoperative period by Doppler ultrasonography examination. The mean serum creatinine level on the 3the and 14the days after the operation was 0.9 (range, 0.5-4 mg/dl) and 0.6 (range $0.5-1.2 \mathrm{mg} / \mathrm{dl}$ ) respectively. Slow graft function was diagnosed in 2patients, with a good perfusion of the allografts showed by renal scan. During a mean follow-up of 4 years, we did not encounter any case of renal artery or venous thrombosis or any suspected arterial stenosis.

Conclusions: The parachute suture technique is safe and straightforward method for arterial and venous anastomosis in renal transplantation with low complication rates. Using aortic punch for arteriotomy facilitates the arterial anastomosis, which may results in excellent kidney function without stenosis of the renal artery.

Keywords: Parachute suture technique; Vascular anastomosis; Kidney transplantation

\section{Introduction}

Renal transplantation becomes the preferred treatment method of end stage renal disease due to advances in surgical techniques, perioperative management, and immunosuppressive regimens. It is more cost-effective than is maintenance dialysis [1] and usually provides the patient with a better quality of life [2]. Surgical techniques have increasingly improved during the past 40 years, reducing surgical complications, morbidity and mortality [3].

Surgical complications in renal transplantation can be divided into lymphocele formation, vascular, ureteric and general surgical complications, such as bleeding and wound infections. Out of these, vascular complications are probably the most dreaded, dramatic, and likely to cause sudden loss of renal allograft $[4,5]$. We present our experience using parachute suture technique and arteriotomy by aortic punch to decrease vascular complication

\section{Patients and methods}

In the present study, from January 2011 through April 2015, hundred renal transplants were done in our center. The vascular part of kidney transplantation is doing by cardiovascular surgeons. All renal anastomosis were done using parachute suture technique and arteriotomy by aortic punch, the technique we are using routinely in coronary aortic bypass graft surgery.

\section{Parachute suture technique}

The iliac fossa approached retroperitoneal through suprainguinal reversed J incision. After mobilizing of iliac arteries and veins, during which the lymphatic channels were ligated, the explanted kidneys were placed in iliac fossa in their final place. The renal veins were anastomosed end-to-side to the common iliac vein or inferior vena cava in recipients, but the site of arterial anastomosis was selected with regard to the allograft position and its renal artery length. Both anastomoses are made with 6-0 monofilament nylon sutures. Here we are explaining the end-to-side anastomosis of renal artery to common iliac artery using aortic punch for arteriotomy and parachute suture technique for anastomosis.

The recipient's iliac artery or aorta is selected as suitable for the anastomosis. The renal artery is then trimmed to an appropriate length. We strive to leave a slight tension on the anastomosis, to avoid kinking once the clamp are removed. We use to spatulated posterior wall of renal arteries, just when the diameter $<3.5 \mathrm{~mm}$. Using an 11 blade, an arteriotomy was performed in the recipient artery small enough to allow the insertion of a single-use 4-mm aortic punch into the lumen providing a clean accurate circular incision (Figure 1).

The anastomosis can be completed with 8-10 stitches in most

*Corresponding author: Abudar Al-Ganadi, Yemen International Hospital, Taiz, Yemen, Tel: 00967-713330342; E-mail: abuthar1978@hotmail.com

Received: September 21, 2015; Accepted: November 11, 2015; Published November 23, 2015

Citation: Al-Ganadi A, Alhamati M, Mughales N, Algunaid A (2015) Parachute Suture Technique with Arteriotomy by using Aortic Punch in Live Related Renal Transplant. J Transplant Technol Res 5: 151. doi:10.4172/2161-0991.1000151

Copyright: (c) 2015 Al-Ganadi A, et al. This is an open-access article distributed under the terms of the Creative Commons Attribution License, which permits unrestricted use, distribution, and reproduction in any medium, provided the original author and source are credited. 
cases; symmetry in the spacing between stitches is important to assure hemostasis.

1) The first bite is Out-In suture was made beginning $3 \mathrm{~mm}$ ahead of the middle of the posterior walls of the renal artery and In-Out of the common iliac artery (Figure 2A).

2) This process is then repeated along the posterior vessel wall, until the posterior walls of both arteries are secured and oriented with a continuous suture (Figure 2B).

3) The sutures are then rinsed with heparinized saline to reduce friction and gentle traction is applied to both ends of the suture, in a direction perpendicular to the axis of the vessels. A pair of atraumatic vascular forceps are used to provide intermittent counter-traction in the direction of the axis vessels. This help distribute tension evenly along the suture, and will allow the vessel walls to "parachute" together (Figure 2C).

4) Through this repeated process, the vessel wall are gradually brought together, then the anterior vessel wall is brought together with a continuation of the running suture. Finally, the anastomosis is finished at the same point of the beginning (Figure 2D). After the last suture, both ends of the suture material are pulled gently, but putting the knot is delayed until unclamping of the external iliac artery. This permits the anastomosis site to become expanded to its widest size, and prevents a purse-string effect at the anastomosis site.

The same method can be used for end-to-end or end-to-side anastomosis of the renal artery or vein.

In all cases, ureteroneocystostomy was performed by modified Lich Gregoir technique. Immunosuppression was given according to standard international protocols. Intraoperative data including the warm and cold ischemic times, and arterial and venous anastomotic times,

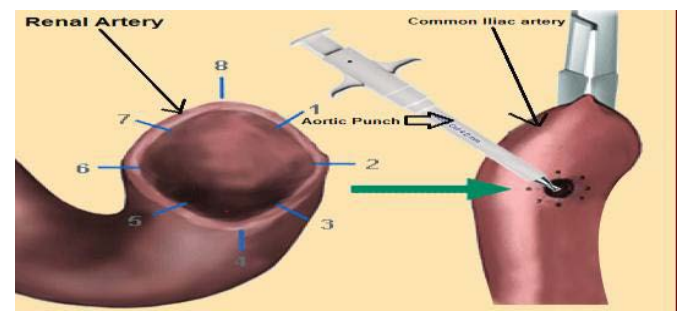

Figure 1: An arteriotomy is created with a No. 11 blade and a $4 \mathrm{~mm}$ aortic punch is used to create a circular arteriotomy.
A.

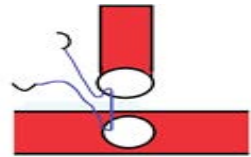

B.

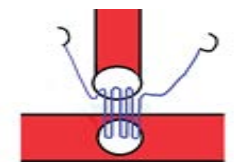

c.

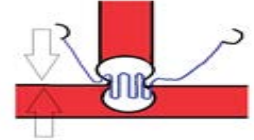

$\mathbf{D}$

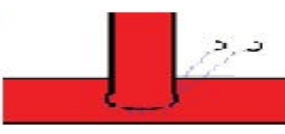

Figure 2: Schematic view of parachute suture technique. are recorded. Follow-up consists of color Doppler ultrasonography examination of the anastomosis site on first and seventh postoperative days, and measuring blood pressure and serum creatinine level daily until postoperative day 14

\section{Results}

Mean age of recipients patients was 23.5 years (range, 15-55 years). Of them 89 males and 11 females patients. All of them have been operated for kidney transplant at Yemen International Hospital from January 2011 through April 2015. All of the live-related donor's nephrectomies were done by laparotomy. Mean kidney warm and cold ischemia time was 7.5 minutes (range: 4-10 minutes) and 21.5 minutes (range: 15-35 minutes) respectively. Mean arterial and venous anastomotic time was 7.2 minutes (range: 6.5-10 minutes) and 8 minutes (range: 5-12 minutes) respectively. All allografts had single artery. Renal arteries were anastomosed to common, external, internal iliac arteries in 53\%, $40 \%$ and $6 \%$ respectively, and $1 \%$ to lower aorta, however allograft renal veins were anastomosed to $95 \%$ common iliac vein and $5 \%$ inferior vena cava recipients.

The mean serum creatinine level on the 3 , an 14 days after the operation was 0.9 (range: $0,5-4 \mathrm{mg} / \mathrm{dl}$ ) and 0.6 (range $0.5-1.2 \mathrm{mg} /$ dl) respectively. No vascular complications were detected in the early postoperative period. Slow graft function (defined as serum creatinine level of $>3 \mathrm{mg} / \mathrm{dL}$ on the 5 day after transplant, but no need for dialysis [6]) was diagnosed in two patients, with a good perfusion of the allografts showed by duplex and CT scan angiography study. At time of this writing, the patients are alive with good graft function, we did not encounter any case of renal artery or venous thrombosis or any suspected arterial stenosis according to the clinical presentations.

\section{Discussion}

Despite, continuous progress in immunosuppressive therapy, surgical technique, prevention and management of infections, vascular complication continue to account for about 3-15\% of the cases of graft dysfunction $[7,8]$. They include transplant renal artery stenosis, arterial and venous thrombosis and postbiopsy arteriovenous fistula and pseudoanuerysm [9].

Refinement of the operative technique for renal transplantation has greatly reduced the rates of surgical complications, morbidity, and mortality in patients. In particular, significant progress has been made with regard to methods of vascular anastomosis [10]. The introduction of the Carrel (end-to-end suturing) patch technique by Alexis Carrelin 1902 is considered to be one of the most important steps in transplant surgery [11]. Since then, many arterial anastomoses have been used at various transplant centers [12-15]. Most of these efforts have been made to reduce kidney ischemic time and risk of transplant artery stenosis, because both warm and cold ischemic time and renal artery stenosis may lead to allograft dysfunction [15-17].

The transplanted renal artery stenosis (TRAS) incidence is between $1 \%$ and $23 \%$ depending upon its definition and diagnostic criteria. It is most common vascular complication seen after renal transplantation. The time of presentation of TRAS may vary from 3 months to 2 years after transplantation [18]. Multiple factors have been implicated in the etiology; suturing technique, intimal trauma during harvesting, kinking or twisting of artery, and atherosclerotic lesions in donor or recipient vessels [19].

Mital and associates, in 1996, performed arterial and venous anastomoses in a kidney recipient using 4-stay sutures and several vascular clips for each anastomosis. The time taken for each anastomosis 
was 8 minutes, and the authors concluded that it is a safe, easy and rapid method of renal vascular anastomosis [20].

Jones presented a sutureless vascular anastomosis technique using vascular clips in 21 recipients. In comparison with conventional running suture technique, the ischemic period reduced by $51 \%$ when clips were used for arterial and venous anastomosis [21].

Simforoosh and associates described the results of 1-suture, 1-knot technique for vascular anastomosis in renal transplant in 386 kidney recipients. They reported no vascular complications in the early postoperative period. This technique was safe, timesaving and especially valuable in obese patients and recipients with deep iliac fossa [14].

Hakim NS performed an end-to-side anastomosis of the renal artery to the external iliac artery; they used an aortic punch for arteriotomy. The use of it in renal transplantation is a technique that facilitates the arterial anastomosis and results in excellent kidney function without stenosis of the renal artery. It is especially useful in living-related transplants and in cases where the renal artery has to be shortened to match the length of the renal vein [22].

Haberal and associates used a corner-saving technique for arterial anastomosis of allograft kidneys in 183 recipients. Renal arterial stenosis was seen in only one patient, and no case of arterial thrombosis was encountered. They concluded that this technique is a safe and easy method of arterial anastomosis, and will decrease the incidence of renal artery stenosis [10].

Zomorrodi and associates during vessel anastomosis between vessel and first knotting of stitching (continue suture with single thread) use $5 \mathrm{~mm}$ distance as expansion space. They found it is safe to make expansion space between the first knot of stitching and the vessel at the anastomosing site for prevention of the pursiness of the vessel and stenosis [15].

Allograft arterial stenosis should be suspected in any recipient who presents with new onset or severe hypertension refractory to medical therapy, unexplained graft dysfunction, and new audible bruit over the graft. Based on these clinical scenarios, we found no cases of renal artery stenosis in the recipients. The patients are alive with good graft function; we did not encounter any case of renal artery or venous thrombosis. This shows safety and good patency of anastomosis using parachute suture technique and arteriotomy by aortic punch. It can be applied even to quite small vessels. The using of aortic punch for arteriotomy is valuable especially in living-related transplants as there are no possibility for aortic patch with renal arteries.

\section{Conclusions}

Based in the present results and the review of the literature, parachute techniques represent valuable option by the shorter time, direct vision of vascular anastomosis, the application in arterial or venous anastomosis and the low complication rates. Additionally use of aortic punch for arteriotomy facilitates the arterial anastomosis, which may results in excellent kidney function without stenosis of the renal artery.

\section{References}

1. United Network for Organ Sharing: (1994) The UNOS Statement of Principles and Objectives of Equitable Organ Allocation. UNOS Update 10:20.

2. Evans RW, Manninen DL, Garrison LP Jr, Hart LG, Blagg CR, et al. (1985) The quality of life of patients with end-stage renal disease. N Engl J Med 312 553-559.

3. Khauli RB (1994) Surgical aspects of renal transplantation: new approaches Urol Clin North Am 21: 321-341.

4. Humar A, Key N, Ramcharan T, Payne WD, Sutherland DE, et al. (2001) Kidney retransplants after initial graft loss to vascular thrombosis. Clin Transplant 15: 6-10.

5. Srivastava A, Kumar J, Sharma S, Ansari MS, Kapoor R, et al. (2013) Vascular complication in live related renal transplant: An experience of 1945 cases. Indian J Urol 29: 42-47

6. Humar A, Johnson EM, Payne WD, Wrenshall L, Sutherland DE, et al. (1997) Effect of initial slow graft function on renal allograft rejection and survival. Clin Transplant 11: 623-627.

7. Jordan ML, Cook GT, Cardella CJ (1982) Ten years of experience with vascular complications in renal transplantation. J Urol 128: 689-692.

8. Kobayashi K, Censullo ML, Rossman LL, Kyriakides PN, Kahan BD, et al (2007) Interventional radiologic management of renal transplant dysfunction: indications, limitations, and technical considerations. Radiographics 27:1109.

9. Gang S, Rajapurkar M (2009) Vascular complication following renal transplantation. JNRT 2: 122-132.

10. Haberal M, Moray G, Sevmis S, Karakayali F, Aydogan C, et al. (2008) Cornersaving renal artery anastomosis for renal transplantation. Transplant Proc 40 145-147.

11. Carrel A: Lyon Med 98:857, 1962.

12. Mosley JG, Castro JE (1978) Arterial anastomoses in renal transplantation. $\mathrm{Br}$ J Surg 65: 60-63.

13. Lee HM (1979) Surgical techniques of renal transplantation. In Morris PJ, ed. Kidney Transplantation. Academic Press/Grune\&Statton, London, UK.

14. Simforoosh N, Gharaati MR, Moslemi MK, Feizzadeh B (2010) One-suture, 1-knot technique in renal vascular transplant. Exp Clin Transplant 8: 224-227.

15. Zomorrodi A, Kakei F, Farshi A, Zomorrodi S (2012) Is Placing an Expansion Space at the Anastomosing Site of the Vessel for Prevention of Pursiness, Safe? J Transplant Technol Res 2:2.

16. Jones JW (1998) A new anastomotic technique in renal transplants reduces warm ischemia time. Clin Transplant 12: 70-72.

17. Bruno S, Remuzzi G, Ruggenenti P (2004) Transplant renal artery stenosis. J Am Soc Nephrol 15: 134-141.

18. ButuroviÄł-Ponikvar J (2003) Renal transplant artery stenosis. Nephrol Dia Transplant 18 Suppl 5: v74-77.

19. Audard V, Matignon M, Hemery F, Snanoudj R, Desgranges P, et al. (2006) Risk factors and long-term outcome of transplant renal artery stenosis in adult recipients after treatment by percutaneous transluminal angioplasty. Am J Transplant 6: 95-99.

20. Jones JW (1998) A new anastomotic technique in renal transplants reduces warm ischemia time. Clin Transplant 12: 70-72.

21. Mital D, Foster PF, Jensik SC, Juan RV, Howard SN, et al. (1996) Renal transplantation without sutures using the vascular clipping system for renal artery and vein anastomosis--a new technique. Transplantation. 62: 1171-1173.

22. Hakim NS, Papalois VE, Romagnoli J (1998) Arteriotomy using the aortic punch in kidney transplantation. Transplant Proc 30: 1800. 